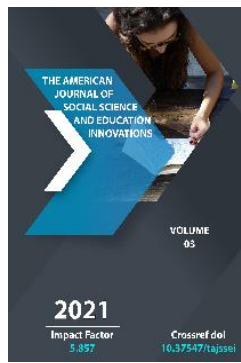

\title{
The Inconsistency Of Language Models
}

\author{
Uralov Azamat Begnarovich \\ Doctor Of Philosophy (PhD) In Philology, Syrdarya Region, Republic Of Gulistan, Uzbekistan
}

Journal Website:

https://theamericanjou

rnals.com/index.php/ta

jssei

Copyright: Original content from this work may be used under the terms of the creative commons attributes 4.0 licence.

\section{ABSTRACT}

The article deals with the problem of disproportion in morpheme units of linguistics and patterns. Based on the disproportion, information is given on the combined affixes formed in the morphemes, the expanded forms, and the analytic and synthetic forms. The data is based on the opinions of the world's leading linguists. The ideas are proven using examples. The formation of a particular linguistic model is a disproportion in the language system (meaning-function-methodological features): confusion of meanings, multifunctionality, semantics, competition in the use of forms (one form has more and more privileges, archaic nation of another form).

\section{KEYWORDS}

Asymmetry, model (pattern), diachrony, synchrony, morpheme, invariant, modelling, affix, expanded form, analytic formant, synthetic formant.

\section{INTRODUCTION}

The various structural units that appear in the synchronous system of language in connection with the processes of asymmetry are inextricably linked with the linguistic model (template, pattern). Because language, in essence, is made up of a number of models at each particular synchronous stage as an opportunity. These are the model, structure, and structural scheme of units such as simple and compound affixes in morphemes, simple compound words in word formation, compound words, simple and compound sentences in syntax. The essence of this model is manifested in the speech process in the form of a variant (concrete form) of invariant (general) unity. 


\section{MATERIALS AND METHODS}

Morphemes have different variants in speech. The use of morphemes varies depending on the style of speech. Such changes determine the specific appeal of the language. While living language and literary language is different, the changes that take place in them are also different. That is why some of the changes that occur in poetic texts occur due to the requirement of rhyme or the requirement of finger weight. In classical poetry, a variant of morphemes is also used to increase the melody. This may be due to the demand for poetry. For example: ko'nglima, ko'nglima, ko'nglim.

Another phenomenon is due to historical developments. This is due to the fact that morphemes take on a unique appearance, change as a result of development, and are influenced by speech and dialect. This change is more historical. Through the phenomenon of synchronism, this process becomes even more visible. Although most scholars believe that there is no phenomenon of synchronism in modern language, we find that the existence of this phenomenon has historically had other forms in the historical variants of many morphemes. This shows that morphemes are used equally in different variants and forms. Historical development is the basis for the formation of modern morphemes, as well as the source for the use of different variants. For example, today's invariant of possessive affixes in words such as " ko'zum, so'zum ... is stopped in the form "- (i) m".

If the variant is dialectal, it is considered dialectal, and its variant only takes on the appearance of the dialect to which it belongs. In some dialects, the use of alternating variants is also observed. We see this in many forms of agreement.
For example, in the phrase "Chechamga ayting uyga bo'laman (Tell Checham I'll be home)", the use of the place-time agreement as a variant of the directional agreement clarifies the issue (in the language dialects version). The use of variants in word formation is also related to phonetic phenomena. In this case, the content adapts to the base or the base adapts to the morpheme. Such a process occurs on the basis of a phonetic phenomenon. A morpheme used in a regular variant changes its composition by adding to the base. Eventually, these options will have their own invariance. For example, the form "-ni" is added to the base " $i$ " in the phonetic variant and becomes "$i$ " (or an " $n$ " is dropped from the base). In other words, there is a phonetic change in the structure of the morpheme. We accept invariants of morphemes no matter how they change their structure. In our language, there are variants of the form [1], which means "the preferred variant, the correct variant, the variant chosen for the literary language":

1. Poetic variant: ko'nglin yarasi, tog'in erkasi, gulin mevasi;

2. Historical version: Yerda qoldi, o, tanim manim, O'zbekiston vatanim manim;

3. Dialectal variant: kitobting juzi, ko'zimding qarosi, bolamding bolasi;

4. Phonetic variant: mening uyim, sening ko'chang;

5. Invariant: maktabning hovlisi, ukamning kitobi.

It should be noted that the right to join the paradigm is given only to the invariant. Therefore, an invariant is selected from the options. Of the above 5 options, access to the agreement paradigm was limited to the invariant form. Each individual form of an affix morpheme with several variants is a separate allomorph. Assumed to be a common invariant morpheme for them, it contains a set of 
allomorphs derived from each other: -gaz (qaz, -kaz, -g‘az), -giz (-kiz, -qiz, -g'iz, -g‘uz) [2].

Modelling should include the most important, basic, invariant features of the object. The same object is not only the external but most importantly, its semantic-functional value (functional semantic side) of the linguistic unit. , both the representative (the content side) have relative independence, enter into a certain proportionality in the synchronous phase, are a member of a paradigm in the language system, and have the status of a single character-unit in the syntagmatic direction.

From the modern paradigm of the verb, the compound affix -moqda (going, coming), which is the main element in the present tense, means that, like other modern forms, the action begins before the time of speech and does not end at the moment of speech.... The meaning of continuity is not present in all forms of time" [3].

However, they differ in meaning or application. For example, "The form of the modern verb with the affix -moqda is typical of the biblical style. It is used in figurative expressions in solemn, uplifting speeches: Kech kuz. Oltinday sap-sariq barglar daraxt shoxlaridan chirt-chirt uzilib erga tushmoqda (Sh. Sharipov) and others. When the verb form with the affix moqda is replaced by the form formed with the affix -yap, the event takes on the form of a simple statement. The reason for the unity of the form formed with the affix -moqda and its use in the third person in relation to the second person, and in the plural in relation to the first and second person singulars also stems from its above-mentioned feature "[3].

Historically, the present tense forms of the verb are in fact the product of the agglutination method of the independent word - the attraction of the verb to the tense paradigm. The verb -yap, -yotib, -yotir forms of the verb have become the tenses of the verb in cases such as bo'layotibdi, borayotir (borayotibdi > borayapti).

How does the verb -moq form of the noun and the form -da of the verb take place in the modern paradigm. According to historical sources, the -moqda form was formed by the subsequent reduction of the analytical form makta turur. For example, in the monument "Oguznoma" this form is used in parallel with the form -guda turur-: ichàgýsin jemakta turur ("devours the insides") -cherikning tanuklapida... jy̋py̌gýda turur [4].

Thus, the long-term model of the verb -moqda is a form in which the function of the predicate in the predicative position diminishes and shortens for a long time before it takes its present position, and allows the -moqda to take its place in the tense category: kelmakda turur > kelmoqdadir > kelmoq through the process and stages.

Hence, it seems that the formation of a particular linguistic model is a disproportion in the language system (meaning-functionmethodological features): confusion of meanings, multifunctionality, semantics, competition in the use of forms (more and more of a form) privilege, the archaic nation of another form). Similar observations can be started by defining and interpreting the history of the formation and application of any model in the language system. The various features of the linguistic model in the object are determined by its functional features application, application, purpose [5].

No matter how different the forms of language models, the state of their application and use is proportional to the system. If the object to be used is selected incorrectly, it will cause various disproportions. The use of such models is particularly noted in speech styles. Several 
methods can be used to model language units: the "dynamic-semiotic" method or the "synthetic" method, and the "direct component determination" or "analytical method" [6].

The main difference between "dynamicsemiotic" ("generative") and "analytical" ("taxonomic") descriptions and descriptions is defined as follows: in the "analytical" approach, ready-made units (simple, compound units) as material (object) ), the morphemes in their composition are determined, and the formal-semantic relationship between the components, the aspects of coordination are indicated. The level of expression and content of the identified morphemes should be proportional. In the "synthetic" approach, on the contrary, preprepared units, words and their forms are not taken, but invariant (abstract, abstract) units, a set of rules. After the application of the rules of word formation, word formation, the formation of commonalities from the features - the direct task of the linguist is to determine the naturally occurring units that reflect the object, which is specific to the linguistic reality of these units. The main condition is the integration of existing models [6].

Therefore, a linguistic understanding is formed by comparing the rules defined within the existing units with the models. Such concepts are ready-made models to express in accordance with the reality of language. The concept is modelled in terms of the emergence of meaning. Otherwise, the language becomes rich in forms and incomprehensible. The presence of the model in the language ensures its consistency and mobility and keeps it in shape.

In Turkic and Uzbek languages, the formation of expanded forms from compound affixes is also a common process.
For example, in the old Uzbek language sources -(a)yin (borayin), -(i)bon (boribon), moqlik (bormoqlik) are considered as a single affix. Subsequently, the semantic-phonetic integrity in the above-mentioned units is lost in the above-mentioned units as a result of the weakening of meaning in the two parts (semantic factor), resulting in the formation of unstressed syllables and even falling in the speech process (phonological factor). They become two units: the basic (go in the form of go, go in the form of go, go in the form of go); The forms -(i)n, -on, -lik become an optional unit that enhances the meaning and function.

A similar but different situation can be seen in examples such as qarilik-qarichilik, yuzakilikyuzakichilik. The meaning of the -chi- in the second part of this pair is weakened, "dimmed", and has the status of a nonpermanent, "optional" part, expressing only the meaning of strengthening, emphasizing the meaning understood from the base.

The order of morphemes in Turkic and Uzbek languages is also unique, they form certain types of morphosyntagmas. Their combination is similar to syntagmatic units - word combinations and sentence structure, and isomorphic: units with a definite meaning are in the preposition, units with a relatively abstract meaning are in the postposition: according to this law, the core morpheme world-forming morphemes precede, in turn, word-forming morphemes before functional word-formers, and functional word-forming morphemes before world-changing affixes [7].

This means that the morphemes that express the exact meaning in this position are arranged from the beginning to the end of the word on the basis of the opposition of "clarityabstraction". In this respect, the latter morphemes are relatively stronger and more important. Such a model is a key feature of the Uzbek language. 
Compound affixes expanded forms, and analytical and synthetic forms formed in morphemes on the basis of disproportion have historically had different forms of "binary" binary contradictions. Compound affixes arise from the functional-semantic rounding of two or more constituents (dehqon+chilik, yog'in+garchilik); and the expanded forms underwent the transformation of the parts of the compound affix into new units (the morpheme baron boribon - bor+ibon borib+on: -on as if morphologically subdivided); In synthetic forms, the combination of base and affix does not have the ability to "come as a word" (boryapman boryap - part is deprived of the ability to use the language independently).

This situation can also be observed in some analytical forms: the -a-formant in the compound of the collapsed text also does not have the ability to use independent syntagmatic.

In analytical forms, the meaning of the second part is relevant, and although the first part has lost its semantic value, it retains its functional value, such as attaching the main and auxiliary morphemes: -a qol-: kela qol; -a tur: ko'ra tur; (i)b chiq: o'qib chiq: In reading compounds, the -a, -(i)b forms of the consonant have reached the point of losing their basic semantic value in the analytical formant.

Modelling of these types of forms is carried out, first of all, on the basis of the functionalsemantic value of their constituent parts, and then on the basis of their external - phoneticphonological, morphological features, the definition of invariant units. Therefore, the concept of the model can be described as a theory of language structure, a mechanism of language in the narrow sense, or a semiotic analogy of structure [8].
In descriptive linguistics, on the basis of the principle of binary, the discrete nature of words and morphemes is determined. L. Bloomfield, one of the founders of structural linguistics, notes that in languages with a complex morphological structure, a hierarchy of constructions can be observed: complex structure - in a multi-morpheme word its components, affixes, modifiers are added in a certain order, multilayered the disassembly of devices should proceed on a simple, binary basis. This binary should reflect the appearance of a specific model within a particular language and model [9].

Another great representative of structural linguistics, Y. Naida, writes that the basic models of the language system should always be taken into account when determining the order of layering of the direct constituent parts [9].

Binary structures define paradigmatic rows invariant units, the speech event of the elements in these structures - the syntagmatic location of the main part (core) and satellite part (in the descriptive direction), the contradiction of central and marginal positions (E. Kurilovich), the permanent part ( can be defined as a constant) and a variable (in glossematics) [9].

\section{CONCLUSION}

Thus, the paradigmatic features of multimorpheme words, the syntagmatic occurrence of paradigm members, are the product of certain patterns formed over the centuries in the language system. Functional-semantic shifts, phonomorphological changes, which occur constantly at different levels of the language system, lead to changes and redefinition of inter-morpheme boundaries. As a result, disproportion allows new morphemes to form. In this case, the correct definition of functional-semantic boundaries in the system 
of morphemes is of great scientific and practical importance.

\section{REFERENCES}

1. Hojiyev A. (1985). Glossary of Linguistic Terms. Tashkent. p. 38.

2. Tojiyev Y. (1992). Uzbek morphemes. Tashkent. p. 23.

3. Grammar of the Uzbek language, Volume II, Volume I. Tashkent. 1975. p. 498.

4. Shcherbak A.M. (1953). On the history of the Uzbek literary language of the ancient period. Academician V.A. Gordlevsky dedicated to his 75th birthday. Mascow. p. 320.

5. Apresyan Yu.D. (1966). Ideas and methods of modern structural linguistics. Moscow. pp. 79-99.

6. Bulygina T.V. (1977). Problems of the theory of morphological models. Moscow. pp. 72-73.

7. Baskakov N.A. Historical and typological morphology of the Turkic languages. - M .; 1979 .-- P. 71.

8. Zasorina L.N. (1974). Introduction to Structural Linguistics. Moscow. p. 257.

9. General linguistics. Linguistic research methods. Moscow. 1973. pp.200-207. 